\title{
Influência ambiental de um fragmento arbóreo localizado numa área urbana na qualidade de vida dos seus moradores
}

\author{
Environmental influence of an arboreal fragment located in an urban area on the thermal comfort \\ and quality of life of the residents \\ Influencia ambiental de un fragmento arbóreo localizado en un área urbana sobre el confort térmico \\ y calidad de vida de los habitantes \\ Anderson MARTELLI ${ }^{1}$ \\ Luís Rogério OLIVEIRA ${ }^{2}$ \\ Lucas DELBIM ${ }^{3}$ \\ ${ }^{I}$ Mestre em Ciências Biomédicas Uniararas; Docente do Curso de Educação Física da Faculdade UNIMOGI - Município de Mogi Guaçu - SP \\ ${ }^{2}$ Técnico da Patrulha Ambiental, Secretaria de Agricultura e Meio Ambiente, Itapira, São Paulo \\ ${ }^{3}$ Mestre em Sustentabilidade e Qualidade de Vida - (UNIFAE). Docente do Curso de Educação Física da Faculdade UNIMOGI - Município de Mogi Guaçu - SP
}

\begin{abstract}
Resumo
O aumento da urbanização das cidades brasileiras, muitas vezes sem planejamento, têm provocado sérios danos ambientais e prejuízos à saúde dos seus moradores. As áreas arborizadas apresentam inúmeros efeitos benéficos no microclima - temperatura e umidade do ar, fatores que contribuem na melhoria do conforto térmico e qualidade de vida dos munícipes. O objetivo deste trabalho foi realizar um estudo descritivo e quantitativo quanto às diferenças de temperatura e umidade relativa do ar em dois locais de um conjunto habitacional denominado Braz Cavenaghi, município de Itapira-SP, com características semelhantes de área, destacando-se pela diferença da vegetação arbórea existente e como essa vegetação pode favorecer conforto térmico dos moradores. Os dados foram coletados em uma área bem arborizada e em um local desprovido de vegetação. Os resultados mostraram que a arborização urbana influencia os valores de temperatura e umidade relativa do ar favorecendo a redução do calor gerado nesse ambiente, ampliação das taxas de evapotranspiração com aumento da umidade do ar desempenhando assim, um importante papel na melhoria das condições ambientais das cidades e qualidade de vida de seus habitantes.
\end{abstract}

Descritores: Microclima; Planejamento de Cidades; Nascentes Naturais.

\section{Abstract}

The increase in urbanization in Brazilian cities, often without planning, has caused serious environmental damage and damage to the health of its residents. The wooded areas have numerous beneficial effects in the microclimate - temperature and humidity of the air, factors that contribute to the improvement of the thermal comfort and quality of life of the residents. The objective of this work was to conduct a descriptive and quantitative study on the differences in temperature and relative humidity in two sites of a housing complex named Braz Cavenaghi, Itapira-SP, with similar characteristics of area, tree vegetation and how this vegetation can favor thermal comfort of the residents. The data were collected in a well-wooded area and in an area devoid of vegetation. The results showed that the urban afforestation influences the values of temperature and relative humidity of the air favoring the reduction of the heat generated in this environment, increasing evapotranspiration rates with increasing air humidity, thus playing an important role in improving the environmental conditions of cities and quality of life of its inhabitants.

Descriptors: Microclimate; City Planning; Natural Springs.

\section{Resumen}

El aumento de la urbanización en las ciudades brasileñas, a menudo sin planificación, ha causado graves daños ambientales y daños a la salud de sus residentes. Las áreas arboladas presentan innumerables efectos benéficos en el microclima - temperatura y humedad del aire, factores que contribuyen en la mejora del confort térmico y calidad de vida de los municipios. El objetivo de este trabajo fue realizar un estudio descriptivo y cuantitativo en cuanto a las diferencias de temperatura y humedad relativa del aire en dos locales de un conjunto habitacional denominado Braz Cavenaghi, municipio de Itapira-SP, con características similares de área, destacándose por la diferencia de la región vegetación arbórea existente y como esa vegetación puede favorecer el confort térmico de los habitantes. Los datos fueron recolectados en un área bien arbolada y en un área desprovista de vegetación. Los resultados mostraron que la arborización urbana influye en los valores de temperatura y humedad relativa del aire favoreciendo la reducción del calor generado en ese ambiente, la ampliación de las tasas de evapotranspiración con aumento de la humedad del aire desempeñando así un importante papel en la mejora de las condiciones ambientales de las ciudades y calidad de vida de sus habitantes.

Descriptores: Microclima; Planificación de Ciudades; Manantiales Naturales.

\section{INTRODUÇÃO}

Dentro de um período de tempo não muito longo, o homem vem trocando o meio rural pelo meio urbano ${ }^{1}$. O fenômeno da urbanização nos municípios brasileiros está sendo crescente e global, com aumento populacional, do espaço ocupado e o acréscimo das mais diversas atividades, transformando drasticamente o ambiente natural em um ambiente construído que vem sofrendo significativa alteração climática, com prejuízo para a qualidade de vida dos residentes nos grandes centros urbanos ${ }^{2,3}$ e o desenvolvimento de muitas patologias relacionadas às alterações climáticas.

Esse crescimento desordenado que inclui a ampliação ou construção de vias, edifícios, residências e de parcelamentos de terra com o aumento da cobertura pavimentada tem favorecido a remoção de grande parte da vegetação existente comprometendo também a fauna local ${ }^{1}$.

Essas alterações implicam diretamente nas modificações climáticas das cidades, causadas pela ausência de espécimes arbórea, sendo elas: maior incidência de radiação solar direta, aumento da temperatura do ar, redução da umidade, modificação da direção dos ventos, aumento da emissão de radiação de onda longa e alteração dos ciclos de precipitação ${ }^{4}$. Essas alterações causam desconforto térmico à população urbana, que, a fim de combater o calor, aumenta os gastos energéticos com climatizadores artificiais ${ }^{4}$.

No ambiente urbano, a árvore é considerada a forma vegetal mais característica, a qual, ao longo da história, tem se incorporado uma estreita relação com 
a arquitetura dos centros urbanos. Está muito bem estabelecido na literatura que a arborização urbana contribui para obtenção de um ambiente urbano agradável e tem influência decisiva na qualidade de vida e na saúde da população ${ }^{5}$, sendo observados menores índices de câncer de pele, diminuição das partículas de poeira no ar, entre outros fatores ${ }^{6}$.

Neste sentido, o ambiente urbano deveria ser um local onde a sensação de conforto da população fosse alcançada, no entanto, em muitos casos, esses ambientes não oferecem condições em referência ao conforto térmico, acústico, luminoso ou visual ${ }^{7}$. Gomes e Amorim ${ }^{8}$ definem conforto térmico como um conjunto de condições em que os mecanismos de autorregulação fisiológica são mínimos ou na zona delimitada por características térmicas em que o maior número de pessoas manifeste se sentir bem. Bartholomei $^{9}$ define como condições para este quadro, fatores como temperatura ambiente, umidade e velocidade do ar, níveis de iluminação e ruídos entre outros, levando em consideração a individualidade de cada pessoa.

Segundo Nicodemo e Primavesi ${ }^{10}$, quando se mantém a temperatura ambiental mais baixa, há maior possibilidade da umidade relativa do ar permanecer em níveis adequados para a saúde e retratam a importância da vegetação para o bem-estar do ser humano com a redução do estresse gerado pela atividade intensa do dia a dia, redução da pressão arterial, batimentos cardíacos e melhoria de outros indicadores fisiológicos.

Por se tratar de uma área pavimentada, a diminuição das áreas verdes na cidade é considerada uma grande modificadora do clima graças ao aquecimento da camada de ar. ${ }^{7}$ Além disso, toda a atividade humana desenvolvida nesses centros urbanos favorece mudanças profundas no clima, alterando temperatura, umidade do ar e as precipitações ${ }^{7}$.

Diante do exposto, o objetivo deste trabalho foi quantificar a contribuição de uma área arborizada, com base em seu conforto térmico, sobre a qualidade de vida dos munícipes, ou seja, atenuação da radiação solar pela vegetação e as influências desta sobre a temperatura e umidade do ar. Tais variáveis foram analisadas em duas áreas com características semelhantes, localizadas em um condomínio residencial denominado Braz Cavenaghi, município de Itapira, estado de São Paulo. Nessas áreas destacase a diferença na vegetação arbórea existente, de modo a subsidiar a discussão da importância da arborização urbana e de áreas verdes arborizadas no conjunto das medidas mitigadoras do aumento da temperatura e favorecimento do conforto térmico, despertando a possibilidade de desenvolvimento de projetos urbanos e arquitetônicos condizentes para uma melhor qualidade de vida da população urbana.

\section{MATERIAL E MÉTODO}

- Áreas de estudo - temperatura e umidade do ar Para análise e comparação da influência da arborização urbana na qualidade de vida dos moradores, dados sobre o microclima - temperatura e umidade do ar foram obtidos por meio das medições nas duas áreas do condomínio residencial denominado Braz Cavenaghi do município de ItapiraSP (ponto amarelo na Figura 1). As duas áreas são paralelas visando condições topográficas semelhantes, distantes 100 metros da região central. Devido à proximidade, pode-se considerar que as áreas de estudo estão sujeitas as influências climáticas similares diferenciando apenas pela proporcionalidade de árvores existente em cada local. A Área 1, desprovida de arborização, estritamente residencial e comercial, solo impermeável e com fluxo de pessoas e veículos (Figura 1-A). A Área 2, local bem arborizado, com uma grande variedade de espécies de médio e grande porte, bem distribuída, apresenta grande parte de solo permeável e pouca intervenção antropogênica (Figura 1-B).

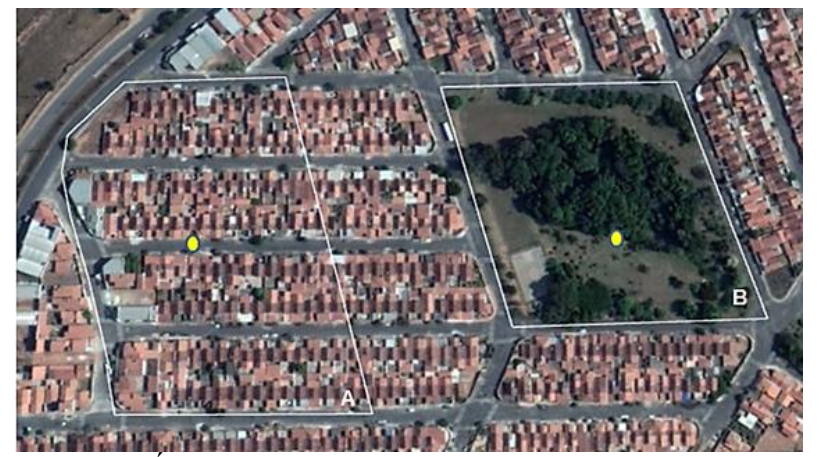

Figura 1: Áreas localizadas no condomínio residencial Braz Cavenaghi, município de Itapira-SP onde foi realizada a coleta de dados - temperatura e umidade do ar. A: Área 1 - desprovida de unidades arbóreas, solo impermeável, estritamente residencial e comercial; B: Área 2, bem arborizada, solo permeável e pouca intervenção antropogênica.

Para a quantificação da temperatura e umidade relativa do ar, foi utilizado Termo-HigroAnemômetro digital (modelo Instrutherm Thar-185). A coleta de dados ocorreu no mês de dezembro/2018, em um único dia, a partir das 12:00h, com condições sinóticas de tempo atmosférico estável, situação de céu limpo, sem nuvens e sem presença de rajadas de vento (velocidade média de $0,4 \mathrm{~km} / \mathrm{h}$ ), o que poderia interferir nos resultados dos dados coletados. O sensor foi posicionado a uma altura de 2,00 metros do solo para captura das variáveis.

A temperatura e umidade relativa do ar foram registrados a cada 30 segundos durante cinco minutos na parte central de cada área totalizando dez medições com um tempo de deslocamento entre uma área e outra de aproximadamente 2 minutos, iniciando as medições na área 1 às 12:00 horas e área 2 - 12:07 horas. Com os dados coletados foi realizada a análise da variância (One Way Anova) com nível de significância em 0,05. 


\section{RESULTADOS E DISCUSSÃO}

Quanto aos parâmetros de temperatura e umidade relativa do ar nas áreas abrangidas por este estudo, os resultados foram significativos $\mathrm{e}$ demonstraram que a arborização existente no perímetro urbano influência de forma considerável as variáveis analisadas - temperatura e umidade relativa do ar. A temperatura medida em graus Celsius $\left({ }^{\circ} \mathrm{C}\right)$ na área 1 , apresentou uma média de $33,8^{\circ} \mathrm{C}$, enquanto que na área 2 , região bem arborizada, a temperatura apresentou uma média de $28,7^{\circ} \mathrm{C}$, uma diferença entre áreas de $5,1^{\circ} \mathrm{C}$. Em referencia à umidade relativa do ar, a área 1, apresentou média de 50,70\% e a área 2, média de 69,60\%, diferença entre áreas de $18,90 \%$ demonstrando o benefício microclimático proporcionado por este fragmento florestal encontrado na área urbana. Os valores relativos às medições de temperatura e umidade relativa do ar podem ser visualizados no Quadro 1 e as variações foram consideradas estatisticamente significativas.

Quadro 1. Valores relativos às medições de temperatura $\left({ }^{\circ} \mathrm{C}\right)$ e umidade relativa do ar (\%) das áreas de estudo

\begin{tabular}{|c|c|c|c|c|}
\hline \multirow{2}{*}{$\begin{array}{l}\text { Número } \\
\text { de coleta }\end{array}$} & \multicolumn{2}{|c|}{$\begin{array}{c}\text { Temperatura (graus } \\
\text { Celsius) }\end{array}$} & \multicolumn{2}{|c|}{ Umidade do ar (\%) } \\
\hline & Área 1 & Área 2 & Área 1 & Área 2 \\
\hline 1 & 33,9 & 28,6 & 50,5 & 69,7 \\
\hline 2 & 34,0 & 28,7 & 50,8 & 69,9 \\
\hline 3 & 33,8 & 28,8 & 50,7 & 69,7 \\
\hline 4 & 33,4 & 28,8 & 50,5 & 69,4 \\
\hline 5 & 33,7 & 28,7 & 50,5 & 69,7 \\
\hline 6 & 34,1 & 28,9 & 50,7 & 69,7 \\
\hline 7 & 33,9 & 28,8 & 50,6 & 69,9 \\
\hline 8 & 33,8 & 28,8 & 50,6 & 69,8 \\
\hline 9 & 33,7 & 28,6 & 51,0 & 68,7 \\
\hline 10 & 33,9 & 28,7 & 51,2 & 69,8 \\
\hline Média & $33,8^{* *}$ & $\mathbf{2 8 , 7}$ & 50,7 & $69,6^{* *}$ \\
\hline
\end{tabular}

Para a temperatura do ar, foi observado que a área 2 mais arborizada, manteve todas as aferições sempre abaixo em relação à área 1 , desprovida de vegetação (Figura 2). Esses dados corroboram com Cruz e Lombardo ${ }^{11}$, onde as temperaturas máximas sempre ficam mais baixas sob a vegetação e as temperaturas mínimas ficam mais elevadas em relação aos locais com pouca ou nenhuma cobertura vegetal. Um estudo realizado por Barreto et al. ${ }^{12}$ no município de Mogi Guaçu-SP, onde foi realizado a medição da temperatura e umidade do ar em uma área arborizada e em outra desprovida de arborização foi observado menores temperaturas e maiores umidades na área arborizada favorecendo maior conforto térmico e qualidade de vida da população residente.

A análise dos dados obtidos demonstrou que a arborização urbana com seu sombreamento proporcionou menor temperatura ambiente. Fragmentos florestais urbanos, apesar de sofrerem ação antrópica e de não terem possibilidade de conexão com outras matas, desempenham forte função social entre os moradores do local $^{13}$ melhorando a qualidade de vida da população e as condições ambientais das cidades ${ }^{14}$. Temperaturas elevadas na área urbana sem vegetação favorecem a criação de um fenômeno denominado Ilhas de Calor Urbano e Amorim ${ }^{15}$ afirma que essas ilhas de calor podem favorecer problemas relacionados ao calor, como o estresse térmico e doenças relacionadas à qualidade do ar.

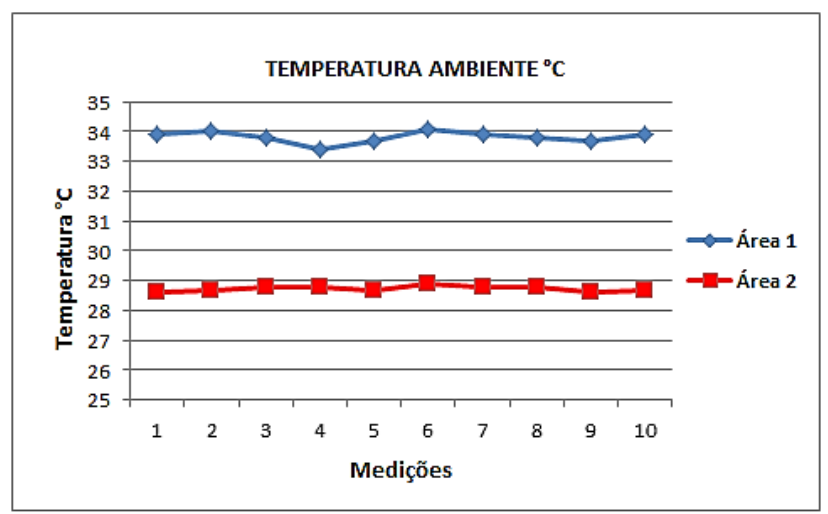

Figura 2: Variações de temperaturas de acordo com a arborização presente em cada área. Área 1 - pouca arborização; área 2 bem arborizada. (Área $1 \neq$ área 2 - p<0.05). (One Way Anova - Teste $t$ Student)

As superfícies vegetadas contribuem para amenizar as condições climáticas, enquanto áreas densamente construídas favorecem a retenção do calor devido à grande concentração de construções e materiais urbanos ${ }^{16}$. Assim, os dados observados com a temperatura do ar deste estudo corroboram com o estudo de Gonçalves et al. $^{7}$ onde áreas que apresentam árvores favoreceram uma temperatura inferior a locais desprovidas de arborização. Gomes e Amorim $^{8}$ analisaram a função da arborização no conforto térmico das praças públicas do municipio de Presidente Prudente, SP e verificaram que a vegetação atua como regulador térmico proporcionando menores valores de temperatura induzindo melhores condições de conforto à população que utiliza esses espaços. A ocorrência de valores elevados de temperaturas nos municipios durante o verão, impulsiona a população a buscar meios que proporcionem um melhor conforto térmico, principalmente em regiões em que a intensidade das ilhas de calor estão associadas a ausência de áreas verdes ${ }^{17}$.

Paradoxalmente aos valores de temperatura, os resultados referentes à umidade relativa do ar na área 2 - arborizada, manteve todas as aferições sempre acima em relação à área 1, (Figura 3), indicando que a arborização através da evapotranspiração favorecem uma maior umidade do ar. Holbrook ${ }^{18}$ relata que as folhas evaporam cerca de $97 \%$ de água por meio da transpiração o que contribui para diminuição da carga de calor na planta e, consequentemente, reduz a temperatura do ambiente através desse eficiente mecanismo desempenhado pelos vegetais. Essa ação leva à diferenças microclimáticas e proporciona temperaturas mais amenas, demonstrando o efeito das 
árvores na melhoria da qualidade de vida dos moradores em ambientes urbanos. ${ }^{1}$ Esses dados corroboram com o estudo de Oke et al. ${ }^{19}$, que a partir de medições na região central da Cidade do México, demonstraram que área profundamente alterada e densamente ocupada, aumentam a temperatura e reduzem a umidade do ar, o que influencia de forma consideravél na sensação térmica de seus moradores e consequentemente na qualidade de vida.

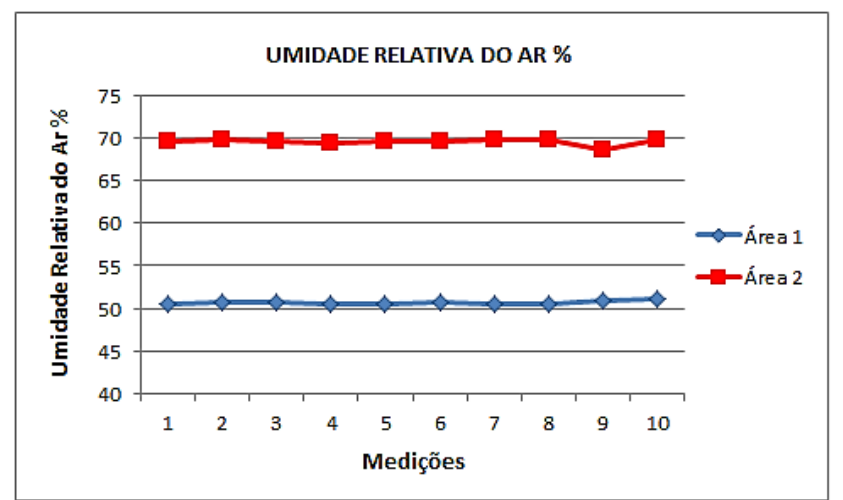

Figura 4: Variações da umidade relativa do ar de acordo com a arborização presente em cada área. Área 1 - pouca arborização; área 2 bem arborizada. (Área $1 \neq$ área 2 - p <0.05). (One Way Anova-Teste $t$ Student)

Martelli e Santos $\mathrm{Jr}^{20}$ verificaram a temperatura e umidade do ar em três áreas do município de Itapira-SP, - área 1, composta por árvores isoladas; área 2 desprovida de arborização e área 3, bem arborizada, sendo observado que a temperatura do ar foi menor na área com intensa arborização e a umidade do ar maior nos locais com arvores, demonstrando como essa vegetação favorece um microclima agradável.

Specian et. al. ${ }^{21}$, analisaram a temperatura e umidade relativa do ar comparando dois ambientes área urbanizada e um remanescente de cerrado, ambos localizados na cidade de Iporá, GO, e os resultados demonstraram diferenças de até $4^{\circ} \mathrm{C}$ de temperatura e $19 \%$ de umidade entre os dois ambientes analisados corroborando com os dados deste estudo. Freitas et al. ${ }^{22}$, referem em seu trabalho que as áreas que apresentaram as maiores médias de temperatura e as menores taxas de umidade relativa do ar estavam localizados em locais com intensa área construída reforçando a função da arborização urbana na manutenção do microclima local nesses locais.

Barreto et al. ${ }^{17}$ relatam em seu estudo o processo autotrófico denominado fotossíntese realizada pelos vegetais, realizando o sequestro de dióxido de carbono $(\mathrm{CO} 2)$ e a liberação de oxigênio $(\mathrm{O} 2)$, e $81,70 \%$ de sua amostra composta por estudantes de Educação Física relataram que esse processo bioquímico realizado pelas unidades arbóreas favorece a melhora da oxigenação tecidual na prática esportiva. Os autores ainda descrevem que 97\% dessa amostra relataram que a qualidade de vida da população está diretamente proporcional à quantidade de árvores existente em um município, sendo reforçado o ambiente agradável proporcionado por essa vegetação, ar puro, melhora da temperatura ambiente e o favorecimento da prática de atividades físicas.

Cada vez mais são reconhecidos os efeitos benéficos que o contato com a natureza gera à saúde humana. Os efeitos positivos do contato com áreas verdes foram observados em relação a longevidade, doenças cardiovasculares, obesidade, saúde mental, qualidade do sono, recuperação de doenças e desfechos de natalidade. ${ }^{23}$

Dadvand et al. ${ }^{24}$ conduziram um estudo com 3.178 crianças escolares relatando que o aumento de áreas verdes no entorno das suas residências foi associado com menor prevalência relativa - $11 \%$ $19 \%$ no sobrepeso/obesidade e comportamento sedentário. Wilker et al. ${ }^{25}$ relataram que a proximidade residencial de áreas verdes foi associada a maiores taxas de sobrevivência após acidente vascular cerebral isquêmico em modelos multivariados ajustados para indicadores de histórico médico, fatores demográficos e socioeconômicos.

Por fim, Pereira et al. ${ }^{26}$ retratam em seu estudo ações de educação ambiental no município de Mogi Guaçu-SP visando o aumento da arborização urbana, definindo que esta ferramenta junto ao tema arborização urbana com alunos e professores das escolas municipais e outros seguimentos da sociedade em geral favorecem a formação de cidadãos conscientes e aptos para decidirem e atuarem na realidade socioambiental com comprometimento visando o bem estar de cada um, da sociedade e da localidade onde vivem.

\section{CONCLUSÃO}

Os resultados demostraram que a arborização existente na área urbana do município de Itapira-SP influencia de forma benéfica a temperatura e umidade relativa do ar favorecendo um microclima agradável melhorando a qualidade de vida da população residente nos centros urbanos. Desta forma, a vegetação arbórea encontrada nas cidades tem papel preponderante no conforto ambiental.

Este estudo evidencia que as áreas verdes no meio urbano e seu uso pela população favorecem um desfecho positivo na saúde de forma geral com redução de quadros estressores, aumento da coesão social e maior interação entre aas pessoas, aumento de práticas esportivas, além dos serviços ambientais prestados por essa vegetação.

Os resultados encontrados ressaltam a importância da conservação e manutenção dos fragmentos de floresta em área urbana, assim como, a arborização encontrada nos passeios públicos, pois proporcionam melhores condições de conforto térmico, contribuindo para a melhoria da qualidade de vida. 


\section{REFERÊNCIAS}

1. Pinheiro CR, Souza DD. A importância da arborização nas cidades e sua influência no microclima. R gest Sust Ambient. Florianópolis. 2017;6(1):67-82.

2. Labaki LC. Vegetação e conforto térmico em espaços urbanos abertos. Fórum Patrimônio. 2011;4(1):23-42.

3. Oliveira MM, Alves WS. A influência da vegetação no clima urbano de cidades pequenas: um estudo sobre as praças públicas de Iporá-GO. Rev Territorial. 2013;2(2):61-77.

4. Abreu LV. Avaliação da escala de influência da vegetação no microclima por diferentes espécies arbóreas [dissertação]. Campinas: Faculdade de Engenharia Civil, Arquitetura e Urbanismo UNICAMP; 2008.

5. Ribeiro FABS. Arborização urbana em Uberlândia: Percepção da população. Rev Católica. 2009;1(1):224-37.

6. Bomfim SS, Giotto AC, Silva AG. Câncer de pele: conhecendo e prevenindo a população. Rev Cient Sena Aires. 2018;7(3):255-59.

7. Gonçalves A, Camargo LS, Soares PF. Influência da vegetação no conforto térmico urbano: Estudo de caso na cidade de Maringá - Paraná. Anais do III Seminário de Pós-Graduação em Engenharia Urbana, 2012.

8. Gomes MAS, Amorim MCCT. Arborização e conforto térmico no espaço urbano: estudo de caso nas praças públicas de Presidente Prudente (SP). Caminhos de Geografia. 2003;7(10):94-106.

9. Bartholomei CLB. Influência da vegetação no conforto térmico urbano e no ambiente construído [tese]. Campinas: Faculdade de Engenharia Civil, Arquitetura e Urbanismo - UNICAMP; 2003.

10. Nicodemo MLF, Primavesi O. Por que manter árvores na área urbana? São Carlos: Embrapa Pecuária Sudeste; 2009.

11. Cruz GCF, Lombardo MA. A importância da arborização para o clima urbano. In: II Seminário Nacional sobre Regeneração Ambiental de Cidades; 2007; Londrina;2007.

12. Barreto AP, Mathias Filho JM, Felisbino RM, Hunger MS, Delbin LR, Magalhães $\mathrm{R}$ et al. Arborização urbana e microclima e a percepção dos acadêmicos de educação física quanto a essa vegetação. Uniciências. 2017;21(2):99-104.

13. Dacanal C, Labaki LC, Silva TML. Vamos passear na floresta! O conforto térmico em fragmentos florestais urbanos. Ambient constr. 2010;10(2):115-32.

14. Lima EM. Aplicação do sistema de informações geográficas para o inventário da arborização de ruas de Curitiba, PR [dissertação]. Curitiba: Universidade Federal do Paraná - UFPR; 2011.
15. Amorim MCCT. Climatologia e gestão do espaço urbano. Mercator. 2010;9(1):71-90.

16. França MS. Microclimas e suas relações com o uso do solo no entorno de escolas públicas na cidade de Cuiabá/MT. ECS. 2012;2(2):148-161.

17. Coltri, PP, Velasco GDN, Polizel JL, Demétrio VA, Ferreira NJ. Ilhas de Calor da estação de inverno da área urbana do município de Piracicaba, SP. In: Simpósio Brasileiro de Sensoriamento Remoto, Florianópolis, 2007. Anais.Florianópolis, 2007.

18. Holbrook NM. Water and Plant Cells. In: Taiz , Zeiger E. (eds.). Plant Physiology. 5. ed. Sunderland: Sinauer Associates, Inc., 2010:67-84.

19. Oke TR, Sproken Smith RA, Jáureghi E, Grimmond CBS. The energy balance of central Mexico City during the dry season. Atmospheric Environment. 1999; 33:3919-30.

20. Martelli A, Santos Jr AR. Arborização Urbana do município de Itapira - SP: perspectivas para educação ambiental e sua influência no conforto térmico. REGET 2015;19(2):1018-31.

21. Specian V, Silva Junior UP, Vecchia FAS. Padrão térmico e higrométrico para dois ambientes de estudo: área urbanizada e remanescente de cerrado na cidade de Iporá-GO. Espaço \& Geografia, 2013;16(1):255-77.

22. Freitas AF, Melo BCB, Cevada CM, Santos JS, Araújo LE. Avaliação microclimática em dois fragmentos urbanos situados no Campus I e IV da Universidade Federal da Paraíba. Rev Bras Geo Fís. 2013;6(4):777-92.

23. Amato-Lourenço LF, Moreira TCL, Arantes BL, Silva-Filho DF, Mauad T. Metrópoles, cobertura vegetal, áreas verdes e saúde Estudos Avançados. 2016;30(86):113-30.

24. Dadvand P, Villanueva CM, Font-Ribera L, Martinez D, Basagna X, Belmonte J et al. Risks and benefits of green spaces for children: a crosssectional study of associations with sedentary behavior, obesity, asthma, and allergy. Environ Health Perspect. 2014;122(12):1329-35.

25. Wilker EH, Wu CD, McNeely E, Mostofsky E, Spengler J, Wellenius GA, Mitleman MA. Green space and mortality following ischemic stroke. Environ Res. 2014;133:42-8.

26. Pereira LBP. O profissional de Educação Física e o meio ambiente: uma experiência de educação ambiental e a melhora da qualidade de vida dos moradores dos centros urbanos Arch Health Invest. 2016;5(4):223-28. 
http://dx.doi.org/10.21270/archi.v8i12.3912

\section{CONFLITO DE INTERESSES}

Os autores declaram não haver conflitos de interesse.

\section{AUTOR PARA CORRESPONDENCIA}

Anderson Martelli

martellibio@hotmail.com

Submetido em 28/12/2018

Aceito em 12/03/2019 